p-ISSN: 2301-4261

e-ISSN: 2621-6418

EMPATI: JURNAL ILMU KESEJAHTERAAN SOSIAL

VOL. 9 NO. 2 Desember 2020

DOI: $10.15408 /$ empati.v9i2.17869

Halaman: 123 - 129

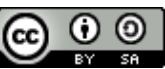

This is an open access article under CC-BY-SA license

\section{PENDEKATAN GROUP WORK DALAM PRAKTIK PEKERJAAN SOSIAL: PENGALAMAN PEKERJA SOSIAL DI LEMBAGA KESEJAHTERAAN SOSIAL (LKS) DI INDONESIA}

\author{
Siti Napsiyah, Ahmad Zaky \\ UIN Syarif Hidayatullah Jakarta \\ Email: siti.napsiyah@uinjkt.ac.id
}

\begin{abstract}
Group work in social work practice is one of methods for social workers' intervention to help the client to cope with their social problems. This research aims to discuss the importance of group work method in social work practices: How they use group work methods, what are the steps of group development process; what are ethical and cultural issues occur during the process? Research method used is qualitative method. Data collection of the research is throughout interview as well as online survey. This research uses also document analysis throughout search engine such as google scholar and google form. The result of the study shows that group work becomes strategic method for social workers to help the client to solve their problems. This study also confirms social workers in social welfare institutions (LKS) in Indonesia are mostly use group work method. Interestingly, this research discuss the issue of cultural and religious ethics in the context of group process in Muslim group and community.
\end{abstract}

Keywords: Social work; group work; group dynamic; cultural sensitivity; negotiation; consensus; conflict resolution.

\begin{abstract}
Abstrak. Pendekatan group work dalam praktik pekerjaan sosial merupakan salah satu pendekatan yang menjadi andalan praktik profesi pekerja sosial dalam memberikan pertolongan kepada klien (individu, kelompok, komunitas, dan organisasi) dalam menyelesaikan masalah. Penelitian ini berusaha untuk menjelaskan tentang metode group work dalam praktik pekerjaan sosial, bagaimana pekerja sosial menggunakan metode group work dalam menyelesaikan permasalahan klien, bagaimana dinamika kelompok muncul dalam proses group work, dan mendiskusikan tentang bagaimana isu etik dan sensitivitas budaya muncul saat proses pelaksanaan group work. Jenis penelitian yang dipilih adalah penelitian kualitatif deskriptif. Studi dokumentasi dilakukan dengan menelusuri sumber-sumber pada mesin pengindeks dan data base yang mendukung open access, seperti google cendekia (google scholar), academia.edu, dan lain-lain. Penelitian juga dilakukan dengan menggunakan survey kepada pekerja sosial melalui google form. Hasil penelitian menunjukkan bahwa metode group work dinilai sebagai pendekatan yang sangat penting bagi pekerja sosial dalam menyelesaikan permasalah sosial yang bersifat kelompok. Hasil penelitian ini juga menunjukkan bahwa dalam proses pelasaksanaan metode group work terdapat dinamika kelompok dan sensitivitas sosial dan agama. Sehingga isu integrasi keilmuan, keislaman dan keindonesiaan menjadi menarik dalam diskusi paper ini.
\end{abstract}

Kata Kunci: Kerja sosial; kerja kelompok, kelompok dinamis; kepekaan budaya; negosiasi; konsensus; penyelesaian konflik.
Open Journal Systems

Read Online

PDF Reader 



\section{PENDAHULUAN}

Pekerjaan sosial merupakan profesi yang saat ini semakin diakui keberadaannya di Indonesia seiring dengan telah disahkannya Undang-Undang tentang Pekerja Sosial, yaitu Undang-undang No. 14 Tahun 2019. Undangundang ini menegaskan bahwa pekerja sosial adalah seseorang yang memiliki pengetahuan, keterampilan, dan nilai praktik pekerjaan sosial serta telah mendapatkan sertifikat kompetensi. Pekerjaan sosial merupakan aktivitas profesional untuk menolong individual, kelompok dan masyarakat dalam meningkatkan atau memperbaiki kapasitas agar berfungsi secara sosial dan mengupayakan kondusivitas dalam mencapai tujuan (Suharto, 2005). Sebagai aktivitas profesional, pekerja sosial memerlukan penguasaan terhadap seperangkat pengetahuan (teoretis), kemampuan mengimplementasikan teori (interpretasi teoretik) dan keterampilan khusus yang diperoleh dari sebuah pengalaman (Hakim, 2014).

Sedangkan, yang dimaksud dengan praktik pekerjaan sosial adalah penyelenggaraan pertolongan professional yang terencana, terpadu, berkesinambungan dan tersupervisi untuk mencegah disfungsi sosial, serta memulihkan dan meningkatkan keberfungsian sosial individu, keluarga, kelompok dan masyarakat. Dalam konteks ini, pekerja sosial yang bekerja dalam setting kelompok memiliki berbagai pilihan pendekatan intervensi dalam membantu klien menyelesaikan masalahnya.

Di Indonesia, pekerja sosial yang bertugas secara fungsional menjalankan peran sebagai pekerja sosial pada umumnya bekerja di Lembaga kesejahteraan sosial (LKS) berbasis lembaga pelayanan sosial, balai rehabilitasi sosal, dan lain-lain (Ariefuzzaman, 2015).

Penelitian ini bertujuan untuk menjelaskan tentang pelaksanaan metode group work dalam praktik pekerjaan sosial; Mendeskripsikan tentang dinamika kelompok (group dynamic) sebagai isu utama dalam group work; dan
Mendeskripsikan jenis-jenis metode group work dalam merespon permasalah sosial yang muncul dalam kerja kelompok di Lembaga kesejahteraan sosial (LKS) di Indonesia.

Penelitian mengenai pendekatan group work dalam praktik pekerjaan sosial belum banyak dilakukan. Meskipun demikian, terdapat banyak kajian terdahulu yang terkait dengan pendekatan dengan kelompok dalam menyelesaikan masalah di masyarakat. Penelitian yang dilakukan oleh Ghina Nadhifah (2020) yang berjudul "Model Group Work dalam Memelihara Kesehatan Mental pada Lanjut Usia di Panti Sosial Tresna Werdha (PSTW) Budi Mulia 3 Jakarta Selatan. Penelitian ini menjelaskan bahwa tipe group work yang digunakan oleh pekerja sosial di PSTW adalah tipe recreation skills group dan social conversation group yang bertujuan untuk meningkatkan interaksi positive dengan orang lain atau bahkan belum saling mengenal satu sama lain, selain itu untuk mengetahui perubahan kemampuan bersosialisasi lansia. Pendekatan Cognitive Behavioural Therapy (CBT) pada lanjut usia yang mengalami insomnia. Yaitu, semacam teknik relaksasi yang dipercaya dapat menurunkan insomnia pada lanjut usia. Teknik ini termasuk dalam pendekatan recreation group, karena mengajak para lansia untuk melakukan aktivitas fisik yang dapat menjadikan lansia lebih tenang dan dapat mengalihkan mereka agar tidak mengalami kecemasan, depresi dan gangguan tidur.

\section{METODE}

Penelitian ini menggunakan metode penelitian kualitatif deskriptif. Penggunaan metode kualitatif bertujuan untuk menggali dan mengumpulkan informasi sebanyakbanyaknya dan sedalam-dalamnya terkait dengan pendekatan group work dalam praktik pekerjaan sosial. Metode penelitian dilakukan dengan menggunakan survey dan penelitian kepustakaan. Penelitian kepustakaan bertujuan untuk menelusuri 
hasil penelitian, buku dan jurnal untuk mendapatkan data awal penelitian dan perbedaan penelitian, sebagaimana dilakukan dalam tinjauan kepustakaan yang dilakukan dalam penelitian lapangan (field research). Metode riset kepustakaan menggunakan koleksi kepustakaan sebagai sumber data tanpa harus menghimpun data lapangan.

Selanjutnya, teknik pengumpulan data dalam penelitian ini dilakukan dengan penelitiaan kepustakaan atau studi dokumentasi. Studi dokumentasi dilakukan melalui penelusuran terhadap sumbersumber pada mesin pencari data seperti google cendekia (google scholar), Academia.edu, dan lain-lain. Penelitian dilakukan secara library research (studi kepustakaan), dengan menelusuri karyakarya ilmiah terdahulu yang dipublikasikan dalam bentuk buku, jurnal, prosiding, seminar, dan publikasi melalui media daring lainnya (internet sources).

Penelusuran dilakukan pada mesin pengindeks seperti google cendekia, SINTA, moraref, dan lain-lain. Penelusuran dilakukan menggunakan kata kunci (keyword) disesuaikan dengan tema, yaitu group work, social work, kesejahteraan sosial, team building, group dynamic. Setiap dokumen yang terlacak, didownload dan dilakukan klasifikasi sesuai dengan tema khusus, seperti pekerja sosial, group work, kerja kelompok, dinamika kelompok, kesejahteraan sosial, dan lain-lain. Selain itu, Teknik pengumpulan data dilakukan dengan menggunakan metode survey (google form) sebagai upaya untuk menggantikan metode wawancara langsung kepada pekerja sosial yang telah melakukan praktik pekerjaan sosial di Lembaga kesejahteraan sosial (LKS) di Indonesia.

Setelah data terkumpul, selanjutnya adalah analisis data. Yaitu mengindentifikasi, klasifikasi, kategorisasi dan membandingkan antar data yang satu dengan data yang lainnya untuk kemudian dibuat kesimpulan.

\section{HASIL DAN DISKUSI}

Dalam praktik pekerjaan sosial dikenal dengan setting praktik pekerjaan sosial yang meliputi tiga pendekatan, yaitu mikro (intervensi individu dan keluarga), mezzo (intervensi terhadap kelompok dan komunitas), makro (intervensi melalui kebijakan dan aksi sosial). Menurut Zastrow, aktivitas praktik pekerjaan sosial di tiga wilayah tersebut meliputi: Social casework, yang bertujuan untuk membantu individu secara tatap muka dan individual untuk mengatasi permasalahan personal dan sosial); case management, yaitu peran pekerja sosial sebagai pengelola kasus klien yang didampingi dalam mencari menyelesaikan masalah agar dapat kembali keberfungsian sosialnya; Group work, yaitu untuk memfasilitasi pengembangan individu baik intelektual, emosional, dan sosial melalui aktivitas kelompok; Group therapy, yaitu yang ditujukan untuk memfasilitasi individu agar dapat beradaptasi baik secara sosial, tingkah laku, dan emosional melalui proses kelompok; Family therapy, yaitu yang bertujuan untuk membantu keluarga yang mengalami permasalahan dalam berinteraksi, perilaku maupun emosi; Community organizing, yaitu untuk memfasilitasi dan mendampingi masyarakat mengidentifikasi, merencanakan, mengorganisasi, mengkoordinasi dan mengadvokasi kebutuhan masyarakat dalam mencapai akses pelayanan sosial maupun hak kesejahteraan hidup lainnya; Administration, yaitu mengarahkan keseluruhan program lembaga pelayanan sosial; Research, yaitu penelitian mengenai hal-hal yang berkaitan dengan pekerjaan atau kesejahteraan sosial; Supervision, yaitu pendampingan dan pengarahan dalam praktek pekerjaan sosial; dan lain-lain (Zastrow, 2009).

Zastrow (2009) menggambarkan bahwa profesi utama yang paling berperan dalam pembangunan kesejahteraan sosial adalah pekerja sosial. Sebagai profesi terdepan dalam pemberian pelayanan sosial untuk membantu orang, baik secara individual, kelompok, keluarga, maupun 
masyarakat dalam memecahkan masalah sosial yang dihadapinya. Kemudian tujuan dari pekerjaan sosial itu sendiri dikemukakan oleh Pincus dan Minahan:

The purpose of social work is "to (1) to enhance the problem solving and coping capacities of people, (2) link people with the systems that provide them with resources, services, and opportunities, (3) promote the effective and human operation of these systems, and (4) contribute to the development and improvement of social policy." (Pincus \& Minahan, 1973)

Penelitian ini membuktikan bahwa pendekatan kelompok atau Group work merupakan suatu pendekatan yang melibatkan beberapa atau banyak orang yang dikumpulkan dalam suatu kelompok. Tujuannya adalah untuk meningkatkan kemampuan dan keberfungsian sosial masing-masing anggota kelompok. Hal ini sebagaimana dijelaskan oleh Soetarso dalam Pengantar Kesejahteraan Sosial (Fahrudin, 2012).

Menurut Sutarso, Group work didasarkan atas pengetahuan mengenai kebutuhan-kebutuhan manusia untuk berhubungan satu sama lain, dan adanya saling ketergantungan diantara mereka. Jadi, pengertian group work dapat dirujuk sebagaimana berikut:

"Group work: An approach to working with personal, and/or interpersonal, and/or social problems that can be directed by the group itself or that can be led or facilitated by an outside person such as a social worker. In what might be termed the classic conception of group work, in which social workers might be involved, the group's interaction is allowed to range widely and be largely self- determining with regard to the type of communication, the content of the discussion, the goals of the group, and how they will be achieved. (Toseland \& Rivas, 2005)

Secara umum, dapat dipahami bahwa group work merupakan suatu metode dengan sekumpulan individu yang didalamnya terjadi interaksi sosial satu sama lain dan saling mempengaruhi serta saling ketergantungan demi tercapainya tujuan yang diharapkan.

Sedangkan praktik pekerjaan sosial menurut UU No. 142019 meliputi: pencegahan disfungsi sosial; perlindungan sosial, rehabilitasi sosial; pemberdayaan sosial; dan pengembangan sosial. Pekerja sosial (professional) merupakan salah satu Sumber Daya Manusia (SDM) penyelenggara kesejahteraan sosial yang dimandatkan oleh Undang-undang RI, 2009, selain tenaga kesejahteraan sosial; relawan sosial; dan penyuluh sosial.

The social worker facilitates by focusing on the perspectives and abilities of group members and how these can be used to achieve their group's goal(s). She/he focuses on assisting the group to see the strengths it has and the support it can provide to its members. There is a dual emphasis on the interaction of the group members, sometimes referred to as the maintenance or process function, and the group's agenda geared towards the achievement of its goals, sometimes referred to as the task or content function." (Toseland \& Rivas, 2005)

Dalam konteks praktik pekerjaan sosial, metode group work dilakukan oleh pekerjaan sosial dalam setting Lembaga Penyelenggaraan Kesejahteraan Sosial (LKS) di bawah Kementerian Sosial Republik Indonesia. Jenjang profesi pekerja sosial yang melakukan metode group work adalah pekerja sosial muda, pekerja sosial fungsional terampil, pekerja sosial ahli, dan lain-sebagainya.

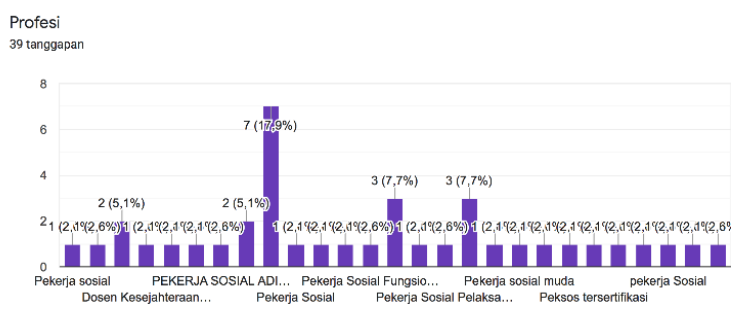


Undang-undang No. 11 tahun 2009 tentang Kesejahteraan Sosial disebutkan bahwa yang dimaksud dengan Lembaga Kesejahteraan Sosial (LKS) adalah organisasi sosial atau perkumpulan sosial yang melaksanakan penyelenggaraan kesejahteraan sosial yang dibentuk oleh masyarakat, baik yang berbadan hukum maupun yang tidak berbadan hukum (Undang-undang RI, 2009).

Pekerja sosial yang praktik metode group work biasanya yang tempat tugasnya adalah berbasis Lembaga Kesejahteraan Sosial (LKS) di bawah naungan Kementerian Sosial Republik Indonesia (RI). Seperti Balai Rehabilitasi Sosial Anak, Balai Rehabilitasi Sosial Remaja, Panti Sosial Tresna Werdha (PSTW), dan Lembaga non-pemerintah seperti save the children, Yayasan tunas cilik, dan lain-sebagainya.

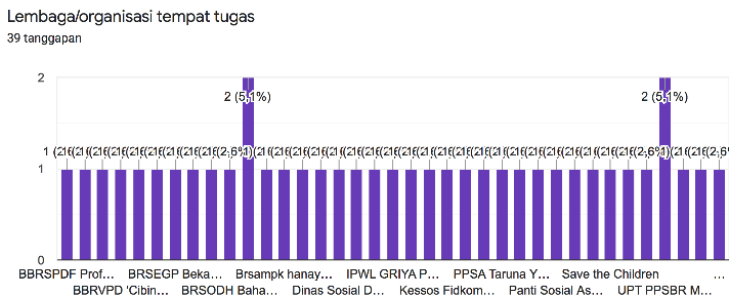

Undang-undang No. 14 Tahun 2019 menyebutkan bahwa penerima manfaat pelayanan praktik pekerjaan sosial meliputi individu, keluarga, kelompok, dan masyarakat. Istilah penerima manfaat dalam pekerjaan sosial disebut dengan klien atau kelompok sasaran (target group). Secara Individu dan keluarga, pekerja sosial memberikan pertolongan kepada seseorang yang mengalami permasalahan psikososial yang dapat mempengaruhi keberfungsiannya di dalam masyarakat. Pekerja sosial dapat menggunakan berbagai pendekatan intervensi dalam memberi pertolongan kepada seseorang tersebut, seperti konseling individu, terapi, dan pendekatan lain yang bersifat casework sesuai dengan permasalahan klien. Secara kelompok, pekerja sosial memberikan pertolongan kepada sejumlah orang yang baik dengan sengaja dikelompokkan oleh pekerja sosial berdasarkan masalah yang dimiliki oleh klien (treatment group) maupun tugas tertentu yang harus diselesaikan oleh klien (task group).

Data penelitian menunjukkan bahwa beberapa kelompok yang menjadi sasaran intervensi pekerja sosial meliputi kelompok gugus tugas (task group) dan kelompok penanganan (treatment group). Mereka adalah Anak yang Berhadapan dengan Hukum (ABH), Anak Korban Penyalahgunaan Napza, Mahasiswa yang mengalami masalah dalam tugas akhir, penyandang disabilitas, Perempuan Rawan Sosial Ekonomi (PRSE), Gelandangan dan Pengangguran, Pengemis, Remaja yang tertangkap tawuran, dan lansia terlantar.

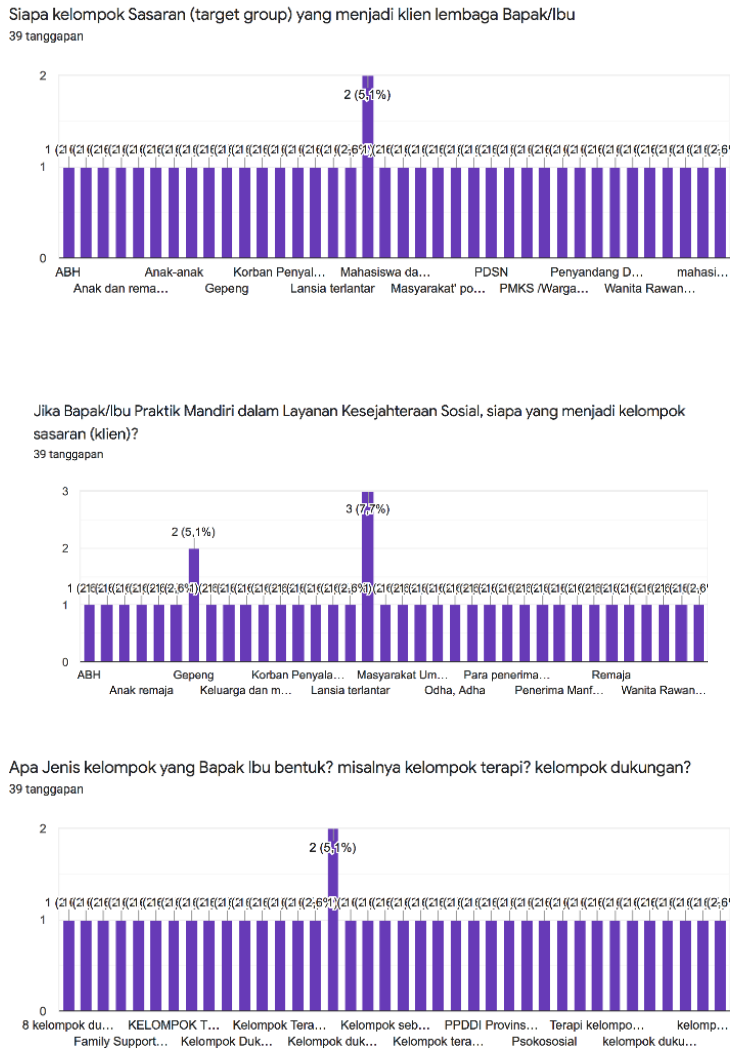

Dalam menentukan kelompok, pekerja sosial menganut asas dan syarat pembentukan kelompok yang meliputi ukuran, komposisi, jumlah anggota kelompok, jenis masalah yang dimiliki masing-masing kelompok, dan lainlain. Tahap pembentukan kelompok ini meliputi: tahap perencanaan (planning); tahap permulaan (beginning); tahap asesmen (assessment); tahap pertengahan (middle); dan 
tahap pengakhiran kelompok (ending) (Toseland \& Rivas, 2005).

Pendekatan group work dalam praktik pekerjaan sosial menjadi menarik untuk didiskusikan dalam konteks negara Indonesia yang mayoritas adalah Muslim. Secara kebetulan, pekerja sosial yang memberikan layanan kesejahteraan sosial bagi klien dalam penelitian ini mayoritas adalah Muslim. Penyelesaian masalah secara bersama merupakan tradisi di masyarakat Indonesia. Masyarakat mematuhi prinsip-prinsip kerja kelompok seperti toleransi (tasamuh), kebersamaan (jamaah), keadilan (musawah), perlindungan, saling mendukung, penyelesaian masalah, dan lain sebagainya.

Di masyarakat, menyelesaiakan masalah anak terlantar misalnya, didapat bahwa pekerja sosial memberikan pendampingan kepada anak yang terlantar di Lembaga kesejahteraan sosial (LKS). Pekerja sosial Muslim mengikuti ajaran agama tentang keharusan memberi pertolongan kepada sesama manusia secara baik. Kerjasama merupakan hal yang harus dilakukan dalam masyarakat. Seperti dalam Al-Qur'an disebutkan:

"Wa ta'awanu allal birri wa taqwa wala ta'awanu 'ala ismi wal u'udwan." (Q.S. AlMaidah:2)

Q.S. Al-Maidah:2 merupakan ayat yang menganjurkan untuk saling memberi pertolongan, mengerjakan kebaikan dan larangan untuk saling tolong-menolong dalam perbuatan dosa dan permusuhan. Dalam Ilmu Pengetahuan Sosial Sosiologi tolong-menolong diartikan sebagai usaha bersama antar individu atau kelompok untuk mencapai tujuan bersama. Dalam buku tersebut disebutkan bahwa tolong-menolong terbagi dalam 4 (empat) jenis, antara lain sebagai berikut: Tolong-menolong Spontan (Spontaneous Reciprocal Assistance), yaitu tolong-menolong serta merta tanpa adanya suatu perintah atau tekanan tertentu; Tolong-menolong Langsung (Directed Reciprocal Assistance), yaitu tolong- menolong yang berasal dari perintah atasan atau penguasa; Tolong-menolong Kontrak (Contractual Reciprocal Assistance), yaitu atas dasar atau perjanjian tertentu; Tolongmenolong Tradisional (Traditional Reciprocal Assistance), yaitu tolongmenolong sebagai suatu sistem sosial.

Sedangkan dalam pelaksanaannya tolong-menolong memiliki bentuk-bentuk, antara lain sebagai berikut: Kerukunan, yaitu bentuk tolong-menolong yang meliputi gotong- royong dan kerjasama; Perundingan (Bargaining), yaitu pelaksanaan pertukaran barang dan jasa antara dua organisasi atau lebih sesuai perjanjian; Kooptasi (Cooptation), yaitu proses penerimaan unsurunsur baru dalam kepemimpinan atau pelaksanaan politik dalam organisasi demi kestabilan organisasi yang bersangkutan; Koalisi (Coalition), yaitu perpaduan dua organisasi atau lebih dengan tujuan yang sama; Joint-Venture, yaitu tolong-menolong dalam pengusahaan proyek-proyek tertentu. Contohnya tolong-menolong dalam pembayaran SPP, tolong-menolong dalam pembangunan jalan.

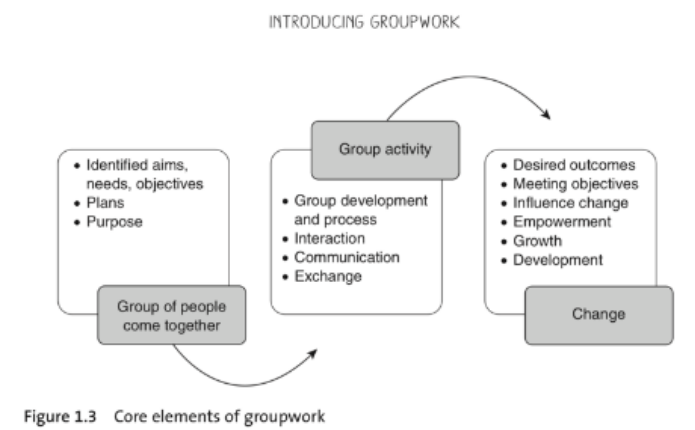

Kesejahteraan sosial memiliki fungsi khusus yaitu mengatasi masalah yang ada kaitannya dengan penyesuaian-penyesuaian sosial dan relasi-relasi sosial serta berfungsi sebagai reorganisasi dari adanya disorganisasi yang bertujuan memberikan atau mengendalikan fungsionalitas dan peranan-peranan sosial dari suatu system yang telah mengalami gangguan atau kekerasan akibat adanya perubahan baik 
dalam tingkat sistem kepribadian maupun sistem sosial.

Pendekatan keagamaan harus dikuasai oleh pekerja sosial. Dalam konseling kelompok mislanya, pekerja sosial dapat menggali masalah klien akan tetapi sumber dan potensi yang dimiliki oleh klien melalui kesadaran klien dalam menyikapi masalah hidup sesuai dengan keimanan yang dimiliki.

\section{KESIMPULAN}

Metode group work merupakan
metode yang sangat relevan untuk
digunakan oleh pekerja sosial dalam
membantu menyelesaikan permasalahan
klien. Hasil penelitian menunjukkan bahwa
metode group work dinilai sebagai
pendekatan yang sangat relevan dalam
konteks praktik pekerjaan sosial dalam
menyelesaikan permasalah sosial yang
bersifat kelompok. Hasil penelitian ini juga
menunjukkan bahwa dalam proses
pelasaksanaan metode group work terdapat
dinamika kelompok dan sensitivitas sosial.

\section{DAFTAR PUSTAKA}

Ariefuzzaman, S. N. (2015). Welfare Approach untuk Indonesia Damai dan Sejahtera: Perspektif Kesejahteraan Sosial. EMPATI: Jurnal IImu Kesejahteraan Sosial, 1(1), 13-23.

Fahrudin, A. (2012). Pengantar kesejahteraan sosial. Refika Aditama.

Hakim, B. R. (2014). Karakteristik dan IsuIsu Social Work Mutakhir di Indonesia. EMPATI: Jurnal Ilmu Kesejahteraan Sosial, 3(1), 1-7.

Nadhifah, G. (2020). Metode Group Work dalam Memelihara Kesehatan Mental pada Lanjut Usia di Panti Sosial Tresna Werdha Budi Mulia 3 Jakarta Selatan. FDIKOM UIN Syarif Hidayatullah Jakarta.

Pincus, A., \& Minahan, A. (1973). Social work practice: Model and method. FE Peacock Pub.

Suharto, E. (2005). Membangun masyarakat memberdayakan rakyat kajian strategis pembangunan kesejahteraan sosial dan pekerjaan sosial. PT Refika Aditama.

Toseland, R. W., \& Rivas, R. F. (2005). An Introduction to Group Work Practice, 5/e. Macmillan New York.

Undang-undang RI. (2009). Undang-undang Republik Indonesia Nomor 11 Tahun 2009 tentang Kesejahteraan Sosial. Undang-Undang RI. (2019). Undang-Undang Republik Indonesia Nomor 14 Tahun 2019 tentang Pekerja Sosial.

Zastrow, C. H. (2009). Social Work with Groups: A Comprehensive Workbook (7th Editio). Brooks/Cole. 